\title{
An analytical solution of groundwater response to tidal fluctuation in a leaky confined aquifer
}

\author{
Jiu Jimmy Jiao \\ Department of Earth Sciences, University of Hong Kong, Hong Kong, People's Republic of China \\ Zhonghua Tang \\ Institute of Environmental Geology, China University of Geosciences, Wuhan, People's Republic of China
}

\begin{abstract}
An analytical solution is derived to investigate the influence of leakage on tidal response in a coastal leaky confined aquifer system. The analytical solution developed here is more general than the traditional solution obtained by Ferris [1951], which can be regarded as a special case of the solution presented in this paper. This solution is based on a conceptual model under the assumption that the groundwater level in the confined aquifer fluctuates in response to sea tide while that of the overlying unconfined aquifer remains constant. This conceptual model is supported by numerous field studies by previous researchers which have demonstrated that the tidal response in an unconfined aquifer may be negligible compared to that in a confined aquifer. The leakage has a significant impact on the tidal behavior of the confined aquifer. Hypothetical studies indicate that both tidal amplitude of groundwater head in the aquifer and the distance over which the aquifer can be disturbed by the sea tide will be considerably reduced because of the existence of leakage. This analytical solution is used to investigate the tidal and piezometer data at the Chek Lap Kok airport, Hong Kong Special Administrative Region, People's Republic of China.
\end{abstract}

\section{Introduction}

In most coastal areas, groundwater and seawater are in constant communication because of tidal fluctuations. Since the 1950 s, research on the dynamic interaction between groundwater and seawater has attracted much attention because of various coastal hydrological, engineering, and environmental problems. These include coastal aquifer parameter estimation, beach dewatering, marine retaining structures, and seawater intrusion [e.g., Ferris, 1951; Farrell, 1994; Svitil, 1996]. This paper will focus on groundwater dynamics in response to tidal fluctuation in a coastal aquifer system.

Ferris [1951] derived an equation to describe the change of groundwater head in a confined aquifer in response to sinusoidal oscillations in sea level. This equation has been widely used to estimate aquifer parameters in coastal areas. In recent years more analytical solutions have been derived to investigate coastal hydrological problems related to tidal dynamics. For example, Li and Chen [1991] use an analytical solution to determine the length of a confined aquifer roof extending under the sea. Sun [1997] developed an analytical solution to understand the groundwater response to tidal fluctuations in an estuary using a two-dimensional tidal loading boundary condition.

In a coastal aquifer system, there is usually an unconfined aquifer above one or more confined aquifers [White and Roberts, 1994; Chen and Jiao, 1998]. The pressure waves in unconfined aquifers tend to be damped because the storage coefficient is usually several orders of magnitude larger than the confined storage coefficient that governs pressure changes at

Copyright 1999 by the American Geophysical Union.

Paper number 1998WR900075.

0043-1397/99/1998WR900075\$09.00 depth [Erskine, 1991]. This phenomenon has also been observed by many other researchers [e.g., White and Roberts, 1994; Millham and Howes, 1995; Chen and Jiao, 1998]. On the basis of a number of case studies in Britain, White and Roberts [1994] concluded that the attenuation of the tidal response with distance varies markedly for confined and unconfined aquifers. Confined aquifers may exhibit low attenuation with fluctuations potentially extending to a hundred meters or more from open water. Unconfined aquifers are heavily damped, and very often, significant fluctuations are unlikely to extend to more than $\sim 20$ or $30 \mathrm{~m}$ from open water. Chen and Jiao [1998] reported that in a particular aquifer system near the South China Sea the unconfined aquifer indicated little tidal effect when the confined aquifers below showed a tidal fluctuation of $0.1-0.6 \mathrm{~m}$.

While the tidal fluctuation in an unconfined aquifer may be negligible compared to that in a confined aquifer, the unconfined aquifer may influence the tidal fluctuation in the underlying confined aquifer via leakage. To the authors' knowledge, there has not been any research to address this issue. In this paper an attempt will be made to develop an analytical solution to investigate the influence of leakage on tidal response in a coastal leaky confined aquifer system. This solution will then be used to discuss the impact of leakage on the tidal behavior of the confined aquifer. The tidal and piezometer data at the Chek Lap Kok (CLK) airport, Hong Kong Special Administrative Region, People's Republic of China are used as a case study.

\section{Problem Setup and Analytical Solution}

Consider a subsurface system with a leaky confined aquifer, an unconfined aquifer, and a semipermeable layer between them (Figure 1). Assume that the shallow unconfined aquifer 


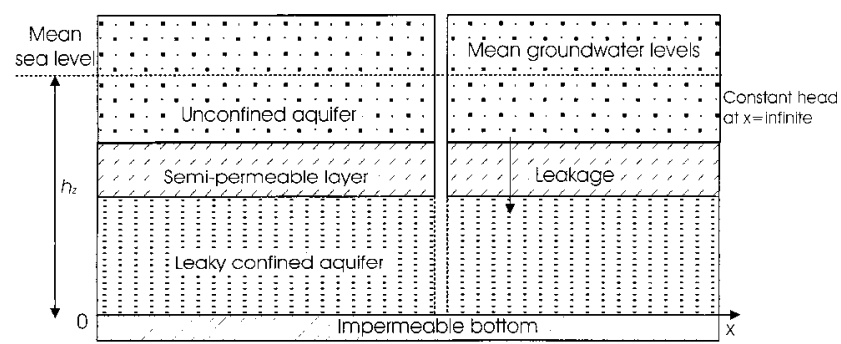

Figure 1. Schematic representation of a leaky confined aquifer system near open tidal water.

has a large specific yield which can damp effectively the tidal effect so that the tidal fluctuation in the unconfined aquifer is negligible compared to that in the confined aquifer. This conceptual model is believed to be reasonable on the basis of the numerous field studies about the significant different tidal responses between confined and unconfined aquifers [e.g., White and Roberts, 1994].

The origin of the $x$ axis is at the intersection of the mean sea surface and the beach face. The $x$ axis is positive landward. The aquifer material is homogeneous and isotopic. The flow velocity in the confined aquifer is essentially horizontal, and there is vertical leakage through the semipermeable layer. The initial groundwater head at time $t=0$ in the whole system is uniform and equals $h_{z}$, which is the distance from the groundwater level to any convenient reference. When $t>0, h_{z}$ in the unconfined aquifer remains constant. Assume that the storage of the semipermeable layer is negligible and that the leakage is linearly proportional to the difference in head between the two aquifers. These assumptions were introduced by Hantush and Jacob [1955] in their benchmark paper about similar leaky aquifer systems. Under these assumptions the governing equation for the one-dimensional groundwater flow in the confined aquifer can be written as

$$
S \frac{\partial h}{\partial t}=T \frac{\partial^{2} h}{\partial x^{2}}+L\left(h_{z}-h\right)
$$

with a tidal boundary

$$
h(0, t)=h_{z}+A \cos (\omega t+c)
$$

where $h(0, t)$ is the head at $x=0, S$ is the storativity, $T$ is the transmissivity, $L$ is the leakance or specific leakage [Hantush and Jacob, 1955; Hantush, 1960], which is the ratio of the hydraulic conductivity $\left(k^{\prime}\right)$ of the semiconfining unit over the thickness $m^{\prime}$ of the semiconfining unit, $A$ is the amplitude of the tidal change, $c$ is the phase shift, and $\omega$ is the tidal speed and equals $2 \pi / t_{0}$, where $t_{0}$ is the tidal period or time for the tide to go from one extreme to the other [Fetter, 1994]; The boundary condition for (1) on the inland side is

$$
h(\infty, t)=h_{z}
$$

which states that the tide has no effect far inland as $x$ approaches infinity.

The equation and boundary conditions from (1) to (3) are very similar to those presented by Sun [1997] to describe groundwater response to tidal fluctuations in an estuary using a two-dimensional tidal loading boundary condition. The major difference is that (1) has a leakage term and is onedimensional. The same analytical approach used by Sun [1997] can be used to solve the above equations. Details are presented in the appendix.

The solution to (1) subject to boundary conditions (2) and (3) is (see appendix)

$$
h(x, t)=h_{z}+A e^{-p x} \cos \left(\omega t-\frac{\omega S}{2 p T} x+c\right)
$$

where $p$ is defined as

$$
p=\frac{1}{\sqrt{2}}\left\{\left[\left(\frac{L}{T}\right)^{2}+\left(\frac{\omega S}{T}\right)^{2}\right]^{1 / 2}+\frac{L}{T}\right\}^{1 / 2}
$$

Assume that the amplitudes of tidal change in the sea and the tidal fluctuation of groundwater level in the confined aquifer are $H_{x}$ and $H_{0}$, respectively. From (4) they have the following relationship:

$$
H_{x}=H_{0} \exp (-p x)
$$

The time lag $t_{\tau}$ between the high tide and the peak of the water level is given by

$$
t_{\tau}=\frac{x S}{2 p T}
$$

\section{Discussion of the Solution}

When $L=0 / \mathrm{d}^{-1}$ there is no leakage from the above unconfined aquifer. Equation (4) becomes

$h(x, t)=h_{z}+A \exp \left(-\sqrt{\frac{\omega S}{2 T}} x\right) \cos \left(\omega t-\sqrt{\frac{\omega S}{2 T}} x+c\right)$

which is essentially the same as the equation derived by Ferris [1951] for confined aquifers without leakage. A hypothetical example is used to demonstrate how leakage influences tidal fluctuations. The following parameter values are used: $T=$ $2000 \mathrm{~m}^{2} / \mathrm{d}^{-1} ; S=0.001 ; h_{z}=0.0 \mathrm{~m} ; c=0.0 ; A=0.65$ $\mathrm{m}$; and $\omega=2 \pi / 24 / \mathrm{d}^{-1}$. On the basis of (6) the amplitude of groundwater head is calculated for different specific leakage $L$ and is presented in Figure 2. The amplitude decreases exponentially with distance from the coast. In the case of leakage the amplitude decreases much faster. As shown in Figure 2, when $L=0$ (no leakage), the amplitude is still $>0$ at the

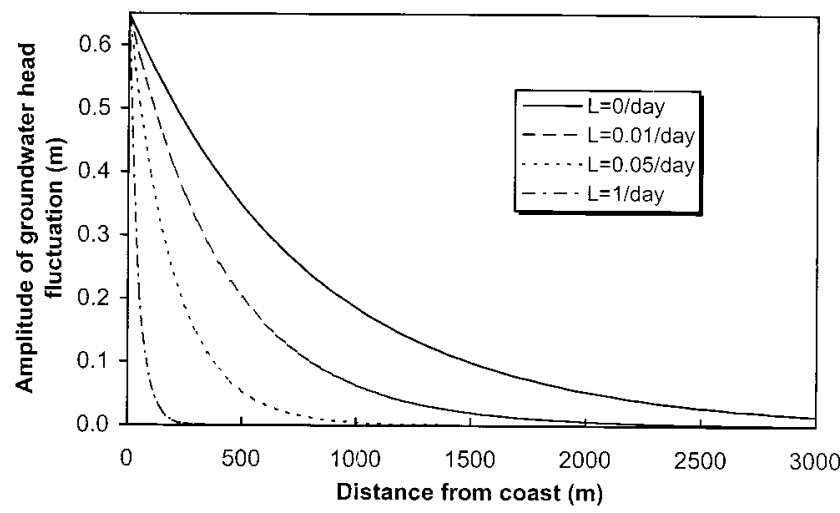

Figure 2. Change of amplitude of groundwater head in the confined aquifer with distance inland at time $t=3$ hours for different specific leakage. 

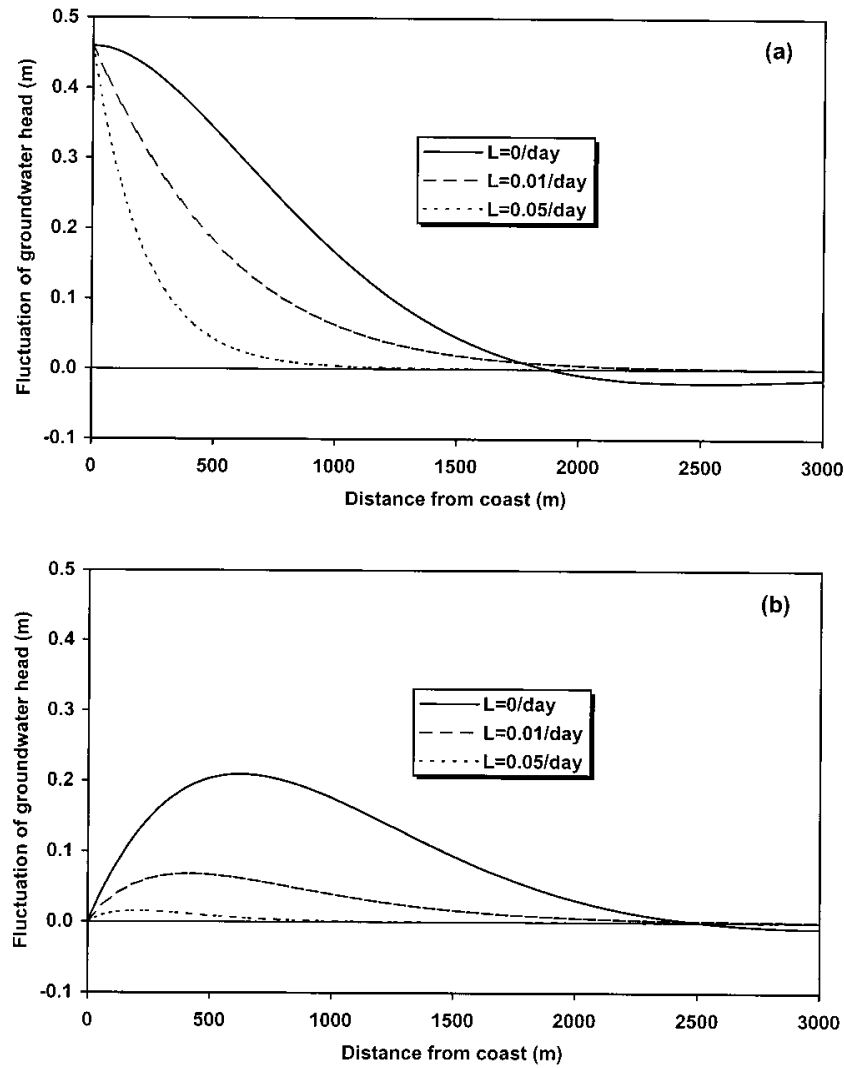

Figure 3. Change of groundwater head in the confined aquifer with distance inland at $t=$ (a) 3 and (b) 6 hours when specific leakage $L=0.0,0.01$ and $0.05 \mathrm{~d}^{-1}$.

distance of over $3000 \mathrm{~m}$, but when $L=1 / \mathrm{d}^{-1}$, the amplitude becomes zero at $\sim 200 \mathrm{~m}$.

On the basis of (4) the actual groundwater head fluctuation in the confined aquifer is calculated and presented in Figure 3. It can be seen that leakage significantly reduces the tidal fluctuation of groundwater. As shown in Figure 3a, if there is no leakage $\left(L=0 / \mathrm{d}^{-1}\right)$, the tidal fluctuation is evident at the distance of over $3 \mathrm{~km}$ from the coastline. However, when $L$ is increased to 0.01 and $0.05 / \mathrm{d}^{-1}$, fluctuations exist only within 2 and $1 \mathrm{~km}$, respectively.

Figure 4 shows how the amplitude at $x=100 \mathrm{~m}$ changes with leakage. When $L=0,0.05$, and $1 / \mathrm{d}^{-1}$, the amplitudes

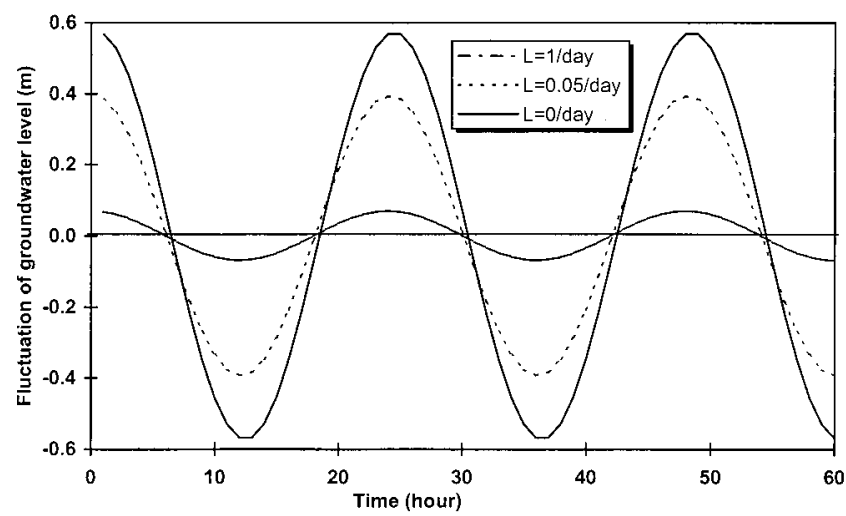

Figure 4. Piezometer head fluctuations at $x=100 \mathrm{~m}$ from the coast when $L 0.0,0.05$, and $1 / \mathrm{d}^{-1}$.

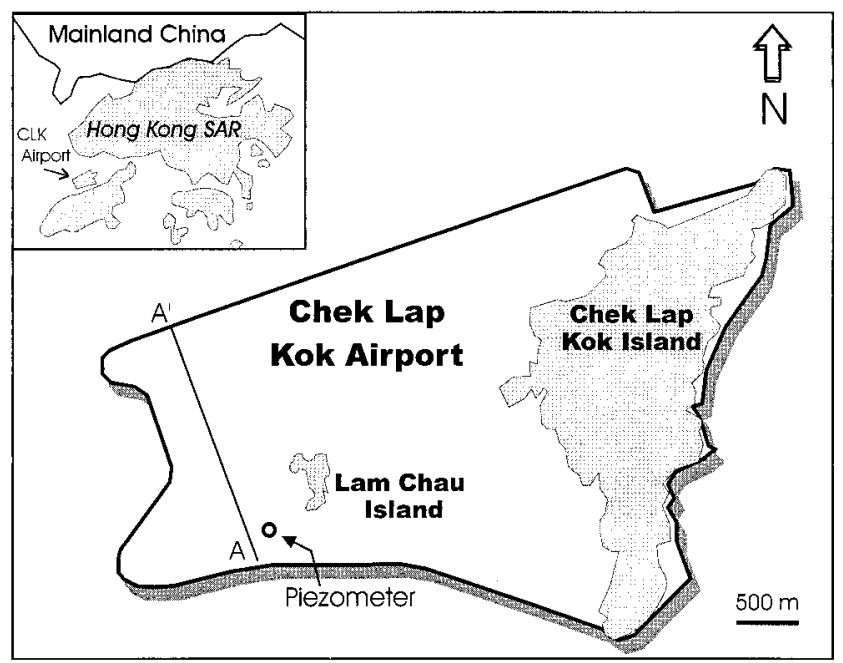

Figure 5. Location of piezometer and the section $\mathrm{A}-\mathrm{A}^{\prime}$ in the Chek Lap Kok (CLP) airport.

are $0.57,0.39$, and $0.07 \mathrm{~m}$, respectively. If the specific leakage is $>1.2 / \mathrm{d}^{-1}$, the amplitude is almost zero, and the fluctuation at this location is undetectable.

Traditionally, the amplitude of groundwater fluctuations and the distance influenced by the sea tide are often used as an indicator of the degree of connection between the confined aquifer and the open water. The lack of tidal influences is considered to be indicative of a low-permeability aquifer with poor hydraulic connection [White and Roberts, 1994]. On the basis of the solution presented here this may be incorrect if the confined aquifer has a vertical hydraulic connection with the overlying unconfined aquifer.

\section{Application to the Aquifer System in Chek Lap Kok Airport, Hong Kong}

\subsection{Background Information}

The $12.48 \mathrm{~km}^{2}$ Chek Lap Kok airport island was formed from excavation of the original islands of Chek Lap Kok and Lam Chau and reclamation of about three quarters of the area from the sea (Figure 5). Detailed geologic and geotechnical information about the airport are given by Wheeler [1996]. A simplified geological section through $\mathrm{A}-\mathrm{A}^{\prime}$ is shown in Figure 6 . The formations in the sequences vary significantly over the site. Bedrock, in the form of moderately decomposed granite, is located some $50 \mathrm{~m}$ below the ground surface. The bedrock is overlain by $\sim 5 \mathrm{~m}$ of completely decomposed granite and alluvial sands and gravels. Next in the sequences is Chek Lap Kok Formation alluvium. The lower part of this formation consists

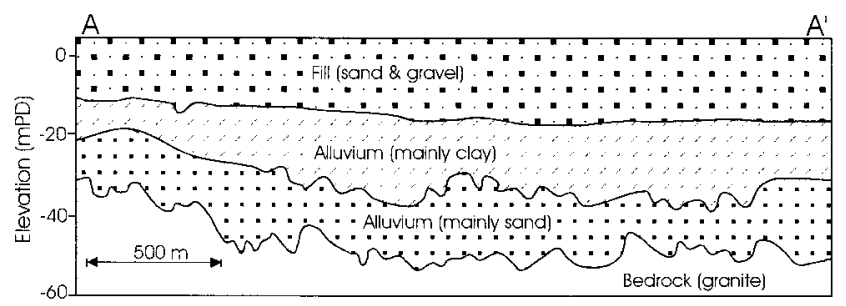

Figure 6. Schematic geological section through $\mathrm{A}=\mathrm{A}^{\prime}$ in Figure 5 [modified from James et al., 1994; Wheeler, 1996]. 


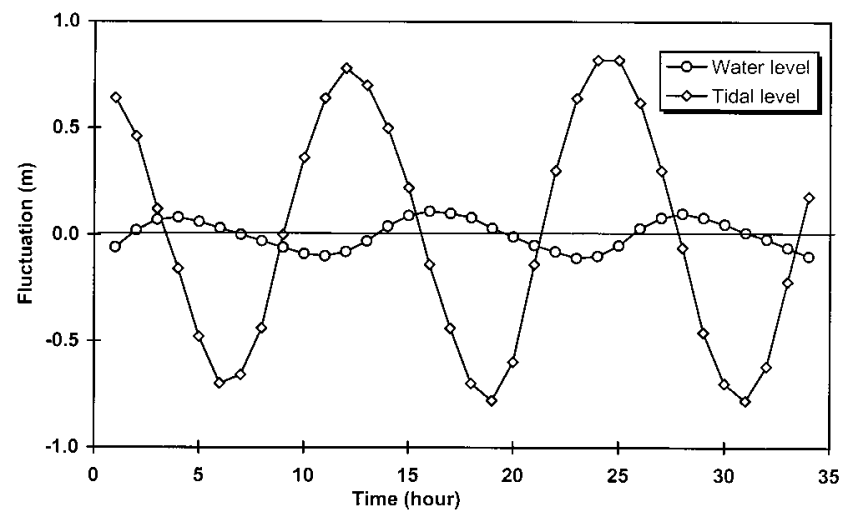

Figure 7. Observed tidal data and groundwater head fluctuation in the confined aquifer at the CLP airport.

mainly of sands and the upper part consists mainly of clay [Wheeler, 1996]. The alluvial sands, together with the completely decomposed granite, become a confined aquifer. The alluvial clay above the sands provides a semipermeable unit. The top layer in the natural sequence was predominantly very soft to soft marine muds. The mud was dredged prior to reclamation and replaced by fill materials, which consist of sands and rock boulders. The fill materials become a very good unconfined aquifer.

The piezometer used for this study is located $\sim 271 \mathrm{~m}$ from the north coast, with a tip level of $-34.5 \mathrm{~m}$ above principle datum (mPD). Piezometer data and tidal data from a nearby tide gauge were collected during the period between 0400 LT on October 2 and 0900 LT on October 3, 1997. This data is shown in Figure 7. The tide is almost semidiurnal [Hong Kong Observatory, 1997]. The amplitude of the tide fluctuation is over $0.8 \mathrm{~m}$, while that of the piezometer head is $\sim 0.1 \mathrm{~m}$. The time lag between the high tide and the peak of the piezometer head is $\sim 4$ hours.

\subsection{Aquifer Parameter Estimation}

Equations (6) and (7) can be used to estimate the hydraulic diffussivity $T / S$ and the specific leakage and transmissivity ratio $T / L$ using the following procedures. The amplitudes $H_{x}$ and $H_{0}$ can be read from the observed tidal and groundwater head curves. The time lag $t_{\tau}$ can also be obtained by examining the curves. The parameter $p$ can be then calculated from (6). After $p$ and $t_{\tau}$ are obtained, $T / S$ can be estimated using (7). Finally, $T / L$ can be estimated using (5).

For the piezometer at the CLK airport the following information is read from the curve: $H_{0}=0.80 \mathrm{~m}, H_{x}=0.10 \mathrm{~m}$, $t_{\tau}=4$ hours, and $t_{0}=12.2$ hours. Using the procedures outlined above, the estimated parameters are $T / S=4.4 \times$ $10^{3} \mathrm{~m}^{2} / \mathrm{h}^{-1} ; T / L=9.2 \times 10^{5} \mathrm{~m}^{2} ;$ and $S / L=207$ hours. $T$ and $L$ could be estimated if $S$ was determined separately by other methods such as studying well logs or conducting pumping tests. Figure 8 shows the observed tidal curve and the calculated curves using the estimated parameters. The two curves match closely.

\section{Summary}

The influence of leakage on the tidal fluctuation in a confined aquifer is studied on the basis of a conceptual model which assumes that the overlying unconfined aquifer has a constant groundwater head and that the leakage is propor-

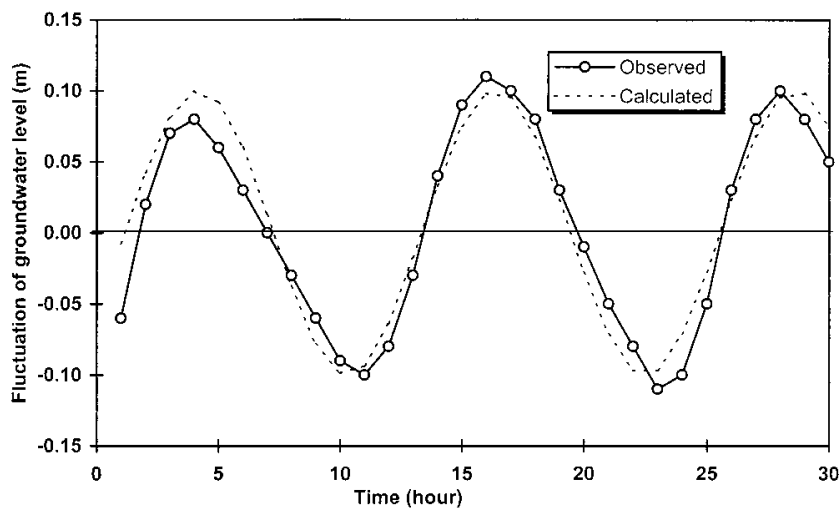

Figure 8. Observed and calculated ground head fluctuations in the piezometer at the CLK airport.

tional to the head difference between the two aquifers. This conceptual model is supported by numerous field studies by previous researchers which indicate that the tidal fluctuation in an unconfined aquifer may be negligible compared to that in a confined aquifer. An analytical solution is derived to investigate the influence of leakage to tidal response in a confined leaky aquifer. The traditional solution obtained by Ferris [1951] can be regarded as a special case of this solution. Both tidal amplitude of groundwater head in the aquifer and the distance over which the aquifer is disturbed by the seawater can be significantly reduced because of leakage. In the case where there is significant leakage from the unconfined aquifer the lack of tidal fluctuations cannot be considered to be indicative of poor hydraulic connection between the confined aquifer and the seawater.

The solution can be used to estimate aquifer parameters such as $T / S$ and $T / L$. The procedures to estimate the parameters are outlined in this paper. By estimating $T / L$ the solution can provide some information on the relative magnitude of leakage. $T$ and $L$ can be estimated if $S$ is determined separately by other methods. The applicability of the solution is demonstrated by investigating the tidal and piezometer data in the CLK airport, Hong Kong, China.

\section{Appendix}

Equations (1) subject to boundary conditions (2) and (3) can be solved by following the similar approach used by Sun [1997]. Letting $H=h-h_{z}$, (1)-(3) become

$$
\begin{gathered}
S \frac{\partial H}{\partial t}=T \frac{\partial^{2} H}{\partial x^{2}}-L H \\
H(0, t)=A \cos (\omega t+c) \\
H(\infty, t)=0
\end{gathered}
$$

From (A2),

$$
H(0, t)=A \operatorname{Re}\left[e^{i(\omega t+c)}\right]
$$

where Re denotes the real part of the complex equation.

Given the form of the boundary condition (A2), the solution for (A1) must be in the form

$$
H(x, t)=A e^{\lambda x} e^{i(\omega t+e)}
$$

Substituting (A5) into (A1) gives 


$$
\lambda^{2}=\frac{i \omega S}{T}+\frac{L}{T}
$$

where $\lambda$ must be a complex number.

Let $\lambda=-p+i q$ for $p>0$. Substituting $\lambda=-p+i q$ into (A6) and equating the real and imaginary parts of both sides of the equation, respectively, give

$$
\begin{aligned}
& p^{2}-q^{2}=\frac{L}{T} \\
& -2 p q=\frac{\omega S}{T}
\end{aligned}
$$

In order to solve for $p$ and $q$, add the square of (A7) and (A8):

$$
p^{2}+q^{2}=\left[\left(\frac{L}{T}\right)^{2}+\left(\frac{\omega S}{T}\right)^{2}\right]^{1 / 2}
$$

Then add (A7) and (A9), where it follows directly from (A8) that

$$
\begin{gathered}
p=\frac{1}{\sqrt{2}}\left\{\left[\left(\frac{L}{T}\right)^{2}+\left(\frac{\omega S}{T}\right)^{2}\right]^{1 / 2}-\frac{L}{T}\right\}^{1 / 2} \\
q=-\frac{\omega S}{2 p T}
\end{gathered}
$$

Substituting $\lambda=-p+i q$ into (A5) and using the tidal boundary condition (A2) lead to

$$
\begin{aligned}
H(x, t) & =A \operatorname{Re}\left\{\exp \left[-p x+i\left(\omega t-\frac{\omega S}{2 p T} x+c\right)\right]\right\} \\
& =A e^{-p x} \cos \left(\omega t-\frac{\omega S}{2 p T} x+c\right)
\end{aligned}
$$

Finally, the solution to (1) subject to boundary conditions (2) and $(3)$ is

$h(x, t)=h_{z}+A e^{-p x} \cos \left(\omega t-\frac{\omega S}{2 p T} x+c\right)$

where $p$ is defined as in (A10).

Acknowledgments. This research is supported by Committee on Research and Conference Grants (CRCG) at the University of Hong
Kong. The authors wish to thank A. Tsang for assistance in collecting tidal and piezometer data. The authors also wish to acknowledge A Pickles, the geotechnical manager at the Airport Authority Hong Kong, for permission to use the data collected from AAHK.

\section{References}

Chen, C. X., and J. Jiao, Numerical simulation of pumping tests in multilayer wells with non-darcian flow in the wellbore, Ground Water, in press, 1999.

Erskine, A. D., The effect of tidal fluctuation on a coastal aquifer in the U. K., Ground Water, 29, 556-562, 1991.

Farrell, E. R., Analysis of groundwater flow through leaky marine retaining structures, Geotechnique, 44, 255-263, 1994

Ferris, J. G., Cyclic fluctuations of water level as a basis for determining aquifer transmissibility, IAHS Publ., 33, 148-155, 1951.

Fetter, C. W., Applied Hydrogeology, 376 pp., Prentice-Hall, Englewood Cliffs, N. J., 1994.

Hantush, M. S., Modification of the theory of leaky aquifers, J. Geophys. Res., 65, 3713-3716, 1960.

Hantush, M. S., and C. E. Jacob, Nonsteady radial flow in an infinite leaky aquifer, Eos Trans. $A G U, 36(1), 95-100,1955$.

Hong Kong Observatory, Tide Tables for Hong Kong, Hong Kong, 1997.

James, J. W. C., C. D. R. Evans, A. Crosby, and B. Humphreys, An interpretation of the marine geology for the replacement airport at Chek Lap Kok, Hong Kong, Tech. Rep. WB/93/34, Br. Geol. Surv., Norttingham, Eng., U. K., 1994.

Li, G., and C. Chen, Determining the length of confined aquifer roof extending under the sea by the tidal method, J. Hydrol., 123, 97-104, 1991.

Millham, N. P., and B. L. Howes, A comparison of methods to determine K in a shallow coastal aquifer, Ground Water, 33, 49-57, 1995.

Sun, H., A two-dimensional analytical solution of groundwater response to tidal loading in an estuary, Water Resour. Res., 33, 1429 $1435,1997$.

Svitil, K. A., Groundwater secrets, Discover, 17, 28, 1996.

Wheeler, P. (Ed.) Geotechnical aspects of Hong Kong's new airport, Ground Eng., 29, suppl., 3-33, 1996.

White, J. K., and T. O. L. Roberts, The significance of groundwater tidal fluctuations, in Groundwater Problems in Urban Areas: Proceeding of the International Conference Organized by the Institution of Civil Engineers and Held in London, 2-3 June 1993, edited by W. B. Wilkinson, pp. 31-42, Thomas Telford, London, 1994.

J. J. Jiao, Department of Earth Sciences, University of Hong Kong, Hong Kong, People's Republic of China. (jjiao@hkucc.hku.hk)

Z. Tang, Institute of Environmental Geology, China University of Geosciences, Wuhan 430074, People's Republic of China.

(Received September 16, 1998; revised October 29, 1998; accepted October 29, 1998.) 
